\title{
The effectiveness of a joint labor-management program in controlling awkward postures of the trunk, neck, and shoulders: Results of a field study
}

\author{
W.M. Keyserling, M. Brouwer, and B.A. Silverstein \\ Center for Ergonomics, The University of Michigan, 1205 Beal Avenue, Ann Arbor, MI 48109, USA
}

(Received May 28, 1992; accepted in revised form August 10, 1992)

\begin{abstract}
Awkward working posture at the trunk, neck and shoulders may be caused by a number of factors, including: workstation layout, visual demands of the job, design of equipment and tools, and work methods. Because awkward posture is a recognized risk factor for the development of fatigue, discomfort, and/or disability, the elimination or reduction of awkward work posture is a major objective of many workplace ergonomic programs.

A longitudinal study was undertaken in a large automotive corporation to evaluate the effectiveness of a participative union-management program in reducing work-related musculoskeletal injuries and disorders, including those caused by awkward postures. Following a one-week training program, plant personnel used checklists to evaluate posture on 335 jobs in selected departments at four participating plants. The results of these evaluations were used to develop an intervention program in each plant for controlling awkward postures. To evaluate the effectiveness of the intervention programs, a subset of 151 jobs was tracked by an independent team of university-based ergonomists who performed comprehensive posture analyses at six-month intervals.

The independent evaluation found that the labor-management teams were generally effective in reducing awkward postures at the trunk and shoulders. There were significant decreases in the time spent in awkward trunk and shoulder postures as a result of interventions that were implemented during the study. However, the teams were not effective in controlling neck postures as the frequency of awkward neck postures actually increased over the course of the study.

Most of the successful intervention projects involved modifications to workstation layout in order to reduce or eliminate low, far, or overhead reaches associated with awkward trunk and shoulder postures. Interventions that required changes in product design or major changes in manufacturing processes were generally not observed during the monitoring period.
\end{abstract}

\section{Relevance to industry}

Awkward working postures can lead to discomfort or injury. This study evaluates the effectiveness of a joint, plant-level labor-management program in controlling worker exposures to awkward postures.

\section{Keywords}

Awkward posture; participative ergonomics; ergonomic intervention programs; job analysis.

\section{Introduction}

Working posture and health

Awkward postures have been associated with a variety of work-related diseases, injuries, and syn-

Correspondence to: W.M. Keyserling, Center for Ergonomics, The University of Michigan, 1205 Beal Avenue, Ann Arbor, MI 48109, USA. dromes that range in severity from temporary fatigue and discomfort to serious occupational disability. In this paper, we evaluate the effectiveness of a joint-labor management program in correcting working conditions that cause awkward postures at the trunk, neck, and shoulders.

A positive relationship between awkward trunk posture and the development of fatigue and musculoskeletal disorders has been demonstrated in several recent investigations. Laboratory studies have shown that trunk flexion, lateral bending, 
and/or axial twisting increase biomechanical stresses on the spinal muscles and intervertebral discs (Andersson et al., 1977; Schultz et al., 1982) and may contribute to substantial levels of local muscle fatigue (Chaffin, 1973). A case study of a spot-welding operation found a positive association between awkward trunk posture and fatigue/reduced productivity (Corlett and Bishop, 1976). Punnett et al. (1991) found significant associations between back pain and trunk flexion/ twisting in an epidemiological study of autoworkers. Back pain has also been associated with occupations that require prolonged sitting (Kelsey and Hochberg, 1988).

Prolonged or repeated elevation of the upper arm (shoulder flexion and/or abduction) has been associated with extreme shoulder fatigue and discomfort in laboratory and field studies (Chaffin, 1973; Hagberg, 1982; Kilbom et al., 1986). Epidemiological studies have found increased reports of disorders such as shoulder tendinitis and thoracic outlet syndrome on jobs that require repeated or prolonged shoulder elevation or extension (Feldman et al., 1983; Hagberg, 1984).

Biomechanical models have shown that extreme neck flexion may cause large load moments at the C7-T1 spinal segment (Harms-Ringdahl et al., 1986). In laboratory and field studies, neck flexion has been shown to be related to neck pain as a function of the angle of flexion, the time spent with the neck flexed and the number of flexions per hour (Hunting et al., 1980; Kilbom et al., 1986; Harms-Ringdahl and Ekholm, 1986). Extension, lateral bending, and axial twisting at the neck have been associated with both neck and shoulder discomfort and disorders (Van Wely, 1970; Tola et al., 1988).

\section{Correcting awkward work postures}

Working posture is determined by the interaction of many factors in the workplace. Features of workstation layout such as the height, location, orientation, and horizontal reach requirements of benches, conveyors, machine control devices, and storage containers determine how a worker must position the body when performing a task. Low or extended reaches may involve significant trunk flexion while lateral reaches may require axial twisting (Corlett and Bishop, 1976; Grandjean,
1985; Keyserling et al., 1988). High or far reaches may involve significant elevation of the shoulder (Grandjean, 1985; Keyserling 1986; Ulin et. al., 1990). Visual demands interact with workstation layout to determine the position of the neck and trunk. In order to properly position the eyes to see important task information, neck/trunk postures such as flexion, extension, and/or twisting may be required when viewing objects that are outside the workers normal line-of-sight (Kilbom et al., 1986; Hsaio and Keyserling, 1991). Hand tool design, particularly the location and orientation of handles interact with the workstation layout to determine the posture of the shoulders and the upper extremities (Tichauer, 1978; Armstrong, 1986; Ulin et al., 1990). The anthropometric characteristics of the worker and individual work methods interact with all of the above factors to determine the specific postures used to perform a job.

Correction of awkward posture (and other occupational ergonomic problems) requires an organized, systematic approach. The U.S. Occupational Safety and Health Administration (OSHA, 1990) has recently issued guidelines that describe desired features in the organization and management of an ergonomics program. According to these guidelines, an ergonomics program should have the following components:

- Worksite analysis, including systematic job evaluations to evaluate worker exposures to ergonomic stress.

- Hazard reduction, including an ongoing process for implementing engineering and administrative controls to reduce or eliminate worker exposures to hazardous levels of ergonomic stress.

- Medical management, including record keeping and early recognition and reporting of symptoms.

- Training and education to assure that workers are sufficiently informed about the ergonomic hazards to which they are exposed.

The OSHA guidelines also recognize management commitment and employee involvement as necessary attributes of an ergonomics program.

In this paper we present the findings of a joint-labor management ergonomics program. Although this program was designed to address a broad spectrum of ergonomic stresses in the 
workplace, we limit the presentation to issues related to awkward posture at the trunk, neck, and shoulders.

\section{Methods}

\section{Objectives and study environment}

The findings reported herein were obtained as part of a 42-month longitudinal study undertaken in a large automotive corporation to evaluate the effectiveness of a joint union-management program in reducing employee exposure to ergonomic risk factors. Data were collected from selected departments at four different work-sites in southeastern Michigan: an engine plant, a metal stamping plant, and two parts distribution warehouses (Silverstein et al., 1990). Overall management of the four-plant project was performed by two full-time administrators, one from the union and one from the company. Activities such as job evaluation to identify ergonomic stresses and the development of control programs to reduce stresses were performed by in-plant teams composed of hourly workers and management personnel who were familiar with the jobs. While day-to-day activities were generally performed within the organizational structure of each plant, regular meetings were held to bring representatives from all four sites together to discuss common problems and exchange ideas.

All plant personnel participated in a one-week training program that included lectures on the fundamentals of ergonomics as well as practical exercises in using a checklist-based method of job analysis. Several representatives from each plant participated in three additional days of ergonomic training to obtain additional experience in job analysis. Other than the training provided in conjunction with the project, most participants had no formal training in ergonomics.

Following training, a total of 335 jobs were analyzed using a series of checklists to identify ergonomic risk factors associated with awkward postures, elevated rates of energy expenditure, manual materials handling, and upper extremity exertions. The results of the checklist evaluations were used by plant personnel for several purposes, including establishing priorities for select- ing jobs for intervention programs to reduce ergonomic risk factors. Detailed descriptions of the checklists as well as baseline (i.e., pre-intervention) results from the analysis of the 335 jobs are reported elsewhere (see Silverstein et al., 1990; Keyserling et al., in press; Keyserling et al., in review) and will not be presented here. This paper will focus instead on the effectiveness of interventions in reducing postural stress at the trunk, neck, and shoulders.

\section{Posture measurement techniques}

In order to measure pre-intervention postures and to evaluate the effectiveness of intervention activities in reducing postural stresses, 151 of the 335 jobs were selected for in-depth longitudinal evaluation performed by an independent team of university-based research personnel. These 151 jobs were not randomly chosen. Because it was expected that jobs with known ergonomic stresses were more likely to be changed than jobs with insignificant stresses, a criterion for selecting a job for the longitudinal study was that the job must have had at least one potentially hazardous ergonomic exposure based on the outcome of the checklist evaluations. Due to this selection criterion, jobs included in the longitudinal study would be expected to have somewhat more serious ergonomic exposures than a randomly-chosen set of jobs. (Note: Jobs selected for the longitudinal study did not necessarily have excessive postural stresses. Other factors, such as the presence of heavy manual materials handling, high energy expenditure demands, and/or repetitive upper extremity motions were used to select the 151 jobs.)

To measure changes in postural risk factors over the course of the study, university personnel performed the independent evaluation on three occasions:

(1) Round 1 (Baseline) - Following completion of the checklist analysis.

(2) Round 2 - Approximately six months after Round 1.

(3) Round 3 (Final) - Approximately six months after Round 2.

Due to delays in completing baseline checklists in selected areas at two of the participating plants, only two rounds of independent posture analysis 


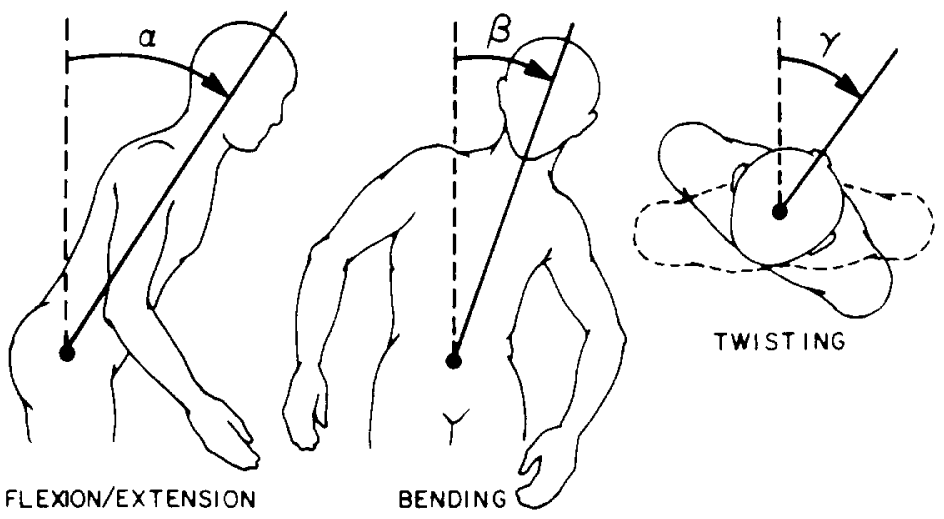

STANDARD TRUNK POSTURES
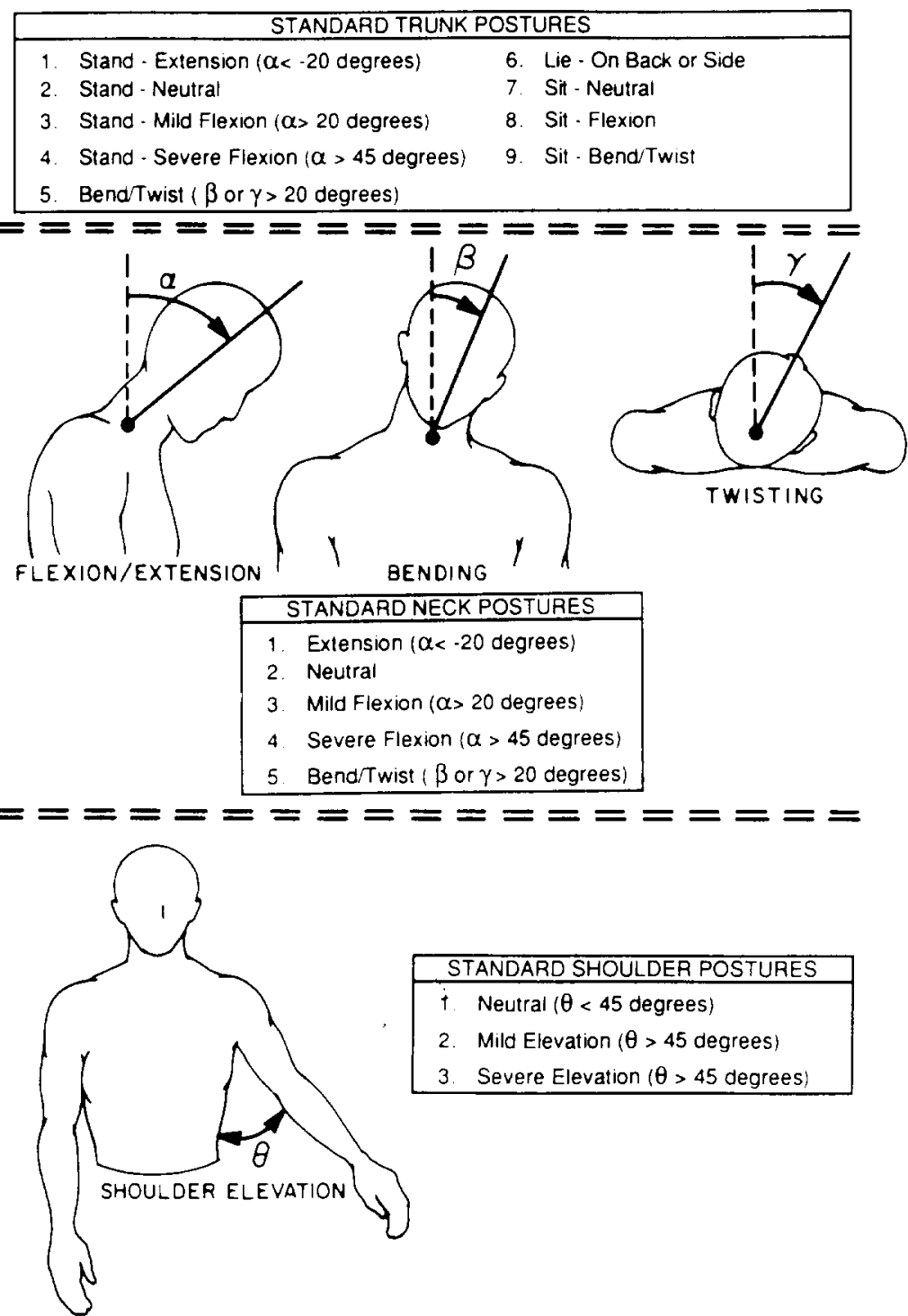

\begin{tabular}{|l|}
\hline STANDARD SHOULDER POSTURES \\
\hline i. Neutral $(\theta<45$ degrees $)$ \\
2. Mild Elevation $(\theta>45$ degrees $)$ \\
3. Severe Elevation $(\theta>45$ degrees $)$ \\
\hline
\end{tabular}

Fig. 1. Standard postures of the trunk, neck, and shoulders used by university personnel in independent analyses of 151 jobs (from Keyserling, 1990). 
could be performed on 39 of the 151 jobs. For these jobs, the Round 2 observations were used as the 'final' results.

During each round of analysis, a videotape was produced of the worker performing the job. The videotape was subsequently analyzed using a computer-aided posture analysis technique (Keyserling, 1990) to determine the amount of time and the percentage of the work cycle that the worker held the trunk, neck, and shoulders in the various postures illustrated in figure 1 . In several instances, the analysis could not be performed at one of the joints due to problems with the videotape (typically the joint was obscured from the camera by equipment or tooling in the workplace). These situations were treated as missing data and the number of jobs in the sample was reduced.

Descriptive statistics (means, standard deviations, minima and maxima) summarizing postures of the trunk, neck, and shoulders were computed for each round of analysis using Michigan Interactive Data Analysis System (MIDAS) software (Fox and Guire, 1976) on an IBM Series 9000 mainframe computer. The paired-t test (Sachs, 1984) was used to compare within-job posture changes between the first and final rounds of independent analyses.

\section{Results}

\section{Baseline postures}

\section{Trunk}

Table 1 presents the results of trunk posture analyses for 149 jobs at Round 1. (Note: The trunk was obscured on the videotapes of two jobs, resulting in a slightly reduced sample size.) The upper section of this table shows the percentage of the work cycle spent in each of the following postures:

(1) Stand - Neutral: The trunk was vertical or nearly vertical with little or no twisting.

(2) Stand - Mild Flexion: The trunk was bent forward between 20 and 45 degrees with little or no twisting.

(3) Stand - Severe Flexion: The trunk was bent forward more than 45 degrees with little or no twisting.
Table 1

Results of Round 1 independent analyses of trunk posture $(n=149)$.

\begin{tabular}{lrrrr}
\hline & \multicolumn{4}{c}{ Observed trunk postures } \\
\cline { 2 - 5 } & Mean & Std. Dev. & Min. & Max. \\
\hline Percent of cycle & & & & \\
Stand - Neutral & 75.8 & 23.7 & 0 & 100 \\
Stand - Mild Flexion & 7.9 & 8.8 & 0 & 36 \\
Stand - Severe Flexion & 6.4 & 12.4 & 0 & 80 \\
Stand - Twisted or Bent & 5.4 & 8.2 & 0 & 37 \\
Sit - Neutral & 2.9 & 15.1 & 0 & 100 \\
Sit - Flexion & 0.5 & 3.4 & 0 & 35 \\
Sit - Twisted & 1.0 & 8.6 & 0 & 80 \\
Other (lying down, etc.) & 0.04 & 0.42 & 0 & 5 \\
& & & & \\
Duration (sec) & & & & \\
Stand - Neutral & 26.8 & 29.8 & 0.0 & 163.5 \\
Stand - Mild Flexion & 2.4 & 3.4 & 0.0 & 27.7 \\
Stand - Severe Flexion & 2.2 & 4.7 & 0.0 & 28.9 \\
Stand - Twisted or Bent & 1.7 & 3.9 & 0.0 & 38.0 \\
Sit - Neutral & 1.3 & 6.9 & 0.0 & 61.9 \\
Sit - Flexion & 0.2 & 1.6 & 0.0 & 18.8 \\
Sit - Twisted & 0.4 & 2.8 & 0.0 & 28.4 \\
Other (lying down, etc.) & 0.1 & 0.54 & 0.0 & 6.2 \\
\hline & & & & \\
\hline
\end{tabular}

(4) Stand - Twisted or Bent: Lateral bending and/or axial twisting exceeded 20 degrees deviation from the neutral.

(5) Sit - Neutral: The trunk was vertical or nearly vertical with little or no twisting.

(6) Sit - Flexion: The trunk was bent forward at least 20 degrees with little or no twisting.

(7) Sit - Twisted or Bent: Lateral bending and/or axial twisting exceeded 20 degrees.

(8) Other - Usually associated with lying on the back or side.

For the 149 baseline jobs, workers spent an average of approximately 21 percent of the work cycle in a non-neutral trunk posture (i.e., any posture other than 'Stand - Neutral' or 'Sit - Neutral'). On average, approximately eight percent of the cycle was spent standing with the trunk in mild flexion, six percent of the cycle was spent standing in severe flexion, and five percent of the cycle was spent standing with the trunk bent or twisted.

The lower section of the table presents descriptive statistics on the duration of any posture during a single work cycle. On average, the duration of non-neutral trunk postures was relatively short, indicating that most jobs did not require prolonged awkward trunk postures. Prolonged 
awkward trunk postures (up to 38 seconds in a twisted, bent posture) were observed, however, on at least a few jobs (see 'maximum' column). Exposures of this length could cause significant fatigue and may increase the risk of back injury.

Table 2 presents the percentage of the work cycle spent in a non-neutral trunk posture, broken down by quintile. Workers spent at least 20 percent of the work cycle in a non-neutral trunk posture on 44 percent of the jobs in the Round 1 data base of independent observations.

\section{Neck}

Table 3 presents the results of neck posture analyses for 110 jobs at Round 1 independent observations. (Note: The neck was obscured on the videotapes of 41 jobs, resulting in a reduced sample size.) The upper section of this table shows the percentage of a work cycle spent in each of the following postures:

(1) Extension: The neck was bent backwards 20 or more degrees (relative to the trunk).

(2) Neutral: The neck was in-line with the trunk or nearly in-line with little or no bending or twisting.

(3) Mild Flexion: The neck was bent forward between 20 and 45 degrees (relative to the trunk) with little or no twisting.

Table 2

Results of Round 1 independent posture analyses. Percentage of cycle time in non-neutral posture by quintile.

\begin{tabular}{lcccc}
\hline $\begin{array}{l}\text { Quintile } \\
\text { (\% of cycle in } \\
\text { non-neutral } \\
\text { posture) }\end{array}$ & \multicolumn{4}{l}{$\begin{array}{l}\text { Number of jobs } \\
\text { (\% of jobs analyzed in category) }\end{array}$} \\
\cline { 2 - 5 } & Trunk & Neck & L.Shldr. & R.Shldr. \\
\hline$<20$ & 83 & 30 & 86 & 65 \\
& $(56)$ & $(27)$ & $(60)$ & $(45)$ \\
$20-40$ & 43 & 34 & 37 & 50 \\
& $(29)$ & $(31)$ & $(26)$ & $(35)$ \\
$40-60$ & 11 & 26 & 13 & 22 \\
& $(7)$ & $(24)$ & $(9)$ & $(15)$ \\
$60-80$ & 4 & 13 & 6 & 3 \\
& $(3)$ & $(12)$ & $(4)$ & $(2)$ \\
$>80$ & 8 & 7 & 2 & 5 \\
& $(5)$ & $(6)$ & $(1)$ & $(3)$ \\
Total & 149 & 110 & 144 & 145 \\
& $(100)$ & $(100)$ & $(100)$ & $(100)$ \\
\hline
\end{tabular}

Table 3

Results of Round 1 independent analyses of neck posture $(n=110)$.

\begin{tabular}{lrrrr}
\hline & \multicolumn{3}{c}{ Observed neck postures } \\
\cline { 2 - 5 } & Mean & Std. Dev. & Min. & Max. \\
\hline Percent of cycle & & & & \\
Extension & 1.9 & 4.9 & 0 & 25 \\
Neutral & 62.6 & 25.5 & 2 & 100 \\
Mild Flexion & 13.9 & 19.6 & 0 & 81 \\
Severe Flexion & 0.6 & 3.5 & 0 & 30 \\
Twisted or Bent & 21.0 & 20.1 & 0 & 86 \\
Duration (sec) & & & & \\
Extension & 0.9 & 2.1 & 0.0 & 10.3 \\
Neutral & 24.4 & 48.5 & 0.6 & 411.0 \\
Mild Flexion & 3.8 & 5.7 & 0.0 & 41.6 \\
Severe Flexion & 0.2 & 0.9 & 0.0 & 6.8 \\
Twisted or Bent & 4.4 & 6.1 & 0.0 & 39.9 \\
\hline
\end{tabular}

(4) Severe Flexion: The neck was bent forward more than 45 degrees (relative to the trunk) with little or no twisting.

(5) Twisted or Bent: The neck was bent sideways or axially twisted more than 20 degrees relative to the trunk.

On average, workers spent about 37 percent of the work cycle in non-neutral neck postures. Approximately 1 percent of the cycle was spent with the neck in extension, 14 percent in mild flexion, and 21 percent in a twisted or bent posture. Less than one percent of the work cycle was spent with the neck in severe flexion.

The lower section of the table presents descriptive statistics on the duration of any neck posture during a single work cycle. On average, the duration of non-neutral neck postures was relatively short, indicating that most jobs did not require prolonged awkward postures. Prolonged awkward neck postures (up to approximately 40 seconds in the mild flexion and twisted categories) were observed, however, on at least a few jobs (see 'maximum' column). Exposures of this length could cause significant fatigue and may increase the risk of neck or upper extremity injuries.

Table 2 (presented earlier) gives the percentage of the work cycle spent in a non-neutral neck posture, broken down by quintile. Workers spent at least 20 percent of the work cycle in a nonneutral neck posture on 73 percent of the jobs. 
Table 4

Results of Round 1 independent analyses of shoulder posture.

\begin{tabular}{|c|c|c|c|c|}
\hline & \multicolumn{4}{|c|}{ Observed shoulder postures } \\
\hline & Mean & Std. Dev. & Min. & Max. \\
\hline \multicolumn{5}{|l|}{ Percent of cycle } \\
\hline \multicolumn{5}{|c|}{ Left shoulder $(n=144)$} \\
\hline Neutral & 77.4 & 19.8 & 0 & 100 \\
\hline Mild Elevation & 20.7 & 17.9 & 0 & 100 \\
\hline Severe Elevation & 1.9 & 4.9 & 0 & 33 \\
\hline \multicolumn{5}{|c|}{ Right shoulder $(n=145)$} \\
\hline Neutral & 73.4 & 20.5 & 0 & 100 \\
\hline Mild Elevation & 23.2 & 18.4 & 0 & 100 \\
\hline Severe Elevation & 2.7 & 6.1 & 0 & 39 \\
\hline \multicolumn{5}{|l|}{ Duration (sec) } \\
\hline \multicolumn{5}{|c|}{ Left shoulder $(n=144)$} \\
\hline Neutral & 27.4 & 40.2 & 0 & 388.8 \\
\hline Mild Elevation & 5.4 & 8.6 & 0 & 73.2 \\
\hline Severe Elevation & 0.7 & 1.7 & 0 & 11.5 \\
\hline \multicolumn{5}{|c|}{ Right shoulder $(n=145)$} \\
\hline Neutral & 23.1 & 26.1 & 0 & 202.5 \\
\hline Mild Elevation & 5.0 & 6.6 & 0 & 53.1 \\
\hline Severe Elevation & 0.9 & 1.8 & 0 & 8.4 \\
\hline
\end{tabular}

\section{Shoulders}

Table 4 presents the results of Round 1 shoulder posture analyses. Left shoulder analyses were performed on 144 jobs; right shoulder analyses were performed on 145 jobs. The upper section of this table shows the percentage of a work cycle spent in each of the following postures:

(1) Neutral: The included angle between the trunk and upper arm was less than 45 degrees.

(2) Mild Elevation: The included angle between the trunk and upper arm was between 45 and 90 degrees.

(3) Severe Elevation: The included angle between the trunk and upper arm was greater than 90 degrees.

Similar postures were observed for the left and right shoulders. On average, workers spent approximately one-fourth of the work cycle in nonneutral postures (23 percent on the left side, 27 percent on the right side). Approximately 22 percent of the cycle was spent with the shoulders in mild elevation ( 21 percent on the left side, 23 percent on the right side), and approximately 2 percent of the cycle was spent with the shoulders in severe elevation.

The lower section of the table presents descriptive statistics on the duration of any posture during a single work cycle. On average, the duration of non-neutral shoulder postures was relatively short, indicating that most jobs did not require prolonged awkward postures. Prolonged mild elevation (up to approximately 73 seconds on the left side and 53 seconds on the right side) occurred on at least a few jobs (see 'maximum' column). Exposures of this length could cause significant fatigue and may increase the risk of shoulder or upper extremity injuries.

Table 2 presents the percentage of the work cycle spent in non-neutral shoulder postures, broken down by quintile, for the left and right shoulders. Workers spent at least 20 percent of the work cycle in a non-neutral left shoulder posture on 40 percent of the jobs and a non-neutral right shoulder posture on 55 percent of the jobs.

\section{Posture changes between baseline and final observations}

To evaluate changes in postural risk factors, results from the final independent analysis were compared to results from the baseline analysis on a job-by-basis. Most jobs were evaluated on three occasions; for these jobs the Round 3 observation was used as the 'final' observation. For the 39 jobs that underwent two rounds of independent analysis, the Round 2 results were used as final observations. Several additional jobs were lost to follow-up for one of the following reasons: (1) the job had been eliminated or substantially changed, therefore comparison was impossible or not meaningful, (2) the operator refused to participate in video taping, (3) machines and/or lines were down for unexpected maintenance, or (4) technical problems with the videotape (e.g., obscured views at one or more joints).

The analyses presented below consider all jobs with at least two rounds of independent observations. Sample sizes are slightly lower than reported for the Round 1 results because of the jobs lost to follow-up. It is important to note that these analyses consider all jobs selected for the longitudinal study, including: (1) those jobs that were not changed during the study period and (2) 
Table 5

Changes in trunk posture between initial and final independent evaluations. Results of 'paired- $t$ ' analyses $(n=141)$.

\begin{tabular}{lcccl}
\hline & \multicolumn{3}{l}{ Observed trunk postures } \\
\cline { 2 - 5 } & $\begin{array}{l}\text { Initial } \\
\text { (mean) }\end{array}$ & $\begin{array}{l}\text { Final } \\
\text { (mean) }\end{array}$ & $\begin{array}{l}\text { Avg. } \\
\text { change }\end{array}$ & Sig. \\
\hline Percent of cycle & & & & \\
Stand - Neutral & 76.8 & 77.3 & 0.5 & n.s. \\
Stand - Mild Flexion & 7.6 & 6.9 & -0.8 & n.s. \\
Stand - Severe Flexion & 5.5 & 3.1 & -2.4 & 0.001 \\
Stand - Twisted or Bent & 5.3 & 4.1 & -1.2 & n.s. \\
Sit - Neutral & 3.0 & 7.1 & 4.1 & 0.025 \\
Sit - Flexion & 0.5 & 0.2 & -0.3 & n.s. \\
Sit - Twisted & 1.1 & 1.2 & 0.1 & n.s. \\
Other (lying down, etc.) & 0.05 & 0.0 & -0.05 & n.s. \\
Duration (sec) & & & & \\
Stand - Neutral & 26.5 & 28.8 & 2.3 & n.s. \\
Stand - Mild Flexion & 2.4 & 2.4 & 0.0 & n.s. \\
Stand - Severe Flexion & 2.1 & 1.6 & -0.5 & n.s. \\
Stand - Twisted or Bent & 1.7 & 1.3 & -0.4 & n.s. \\
Sit - Neutral & 1.4 & 4.5 & 3.2 & 0.06 \\
Sit - Flexion & 0.18 & 0.26 & -0.16 & n.s. \\
Sit - Twisted & 0.4 & 0.6 & 0.2 & n.s. \\
Other (lying down, etc.) & 0.07 & 0.0 & -0.07 & n.s. \\
\hline
\end{tabular}

those jobs that were changed for reasons other than postural stress. (Note: Other ergonomic factors such as forceful exertions during manual materials handling, repetitive motions, and/or high metabolic rates may have been the primary motivation to change a job. Data collected during the study did not allow us to identify those jobs that were modified only to resolve concerns for excessive postural stress.)

\section{Trunk}

The 'paired- $t$ ' test was used to compare within-job changes in work posture requirements that occurred between the baseline and final observations. The results of analyses of trunk postures are presented in table 5 for the 141 jobs that underwent at least two rounds of independent analyses. (Note: There are slight differences between the values given for the baseline round in table 5, and the values given in table 1 . These differences are due to a slightly smaller data set in table 5 because of the jobs lost to follow-up.) The percentage of the work cycle spent in neutral postures (either standing or sitting) increased between the initial and final observations. The in- crease in seated neutral postures (from 3.0 to 7.1 percent of the work cycle) was significant ( $p<$ 0.05 ). In general, the percentage of the work cycle spent in non-neutral postures decreased between the initial and final observations. (The exception to this trend was the 'sit-twisted' posture which showed a slight, but insignificant, increase.) The decrease in severe trunk flexion (from 5.5 to 3.1 percent of the work cycle) was also significant $(p<0.001)$. This change was associated with interventions such as the installation of lift tables and elevated racks that eliminated the need to bend down to floor level.

Similar results were obtained when considering the duration of time spent in any posture (see the lower portion of table 5). In general, the duration increased for neutral postures and decreased for non-neutral postures. (The exception to this trend was the 'sit-twisted' posture.)

In summary, the independent evaluations found that trunk postures generally improved as a result of interventions that were implemented during the project period.

Neck

The results of the paired- $t$ analyses of neck postures $(n=107)$ are presented in table 6 . The percentage of the work cycle spent in mild flexion and severe flexion increased significantly between the initial and final observations (from 14.7 to

Table 6

Changes in neck posture between initial and final independent evaluations. Results of 'paired-t' analyses $(n=107)$.

\begin{tabular}{lcccc}
\hline & \multicolumn{3}{l}{ Observed neck postures } \\
\cline { 2 - 5 } & $\begin{array}{l}\text { Initial } \\
\text { (mean) }\end{array}$ & $\begin{array}{l}\text { Final } \\
\text { (mean) }\end{array}$ & $\begin{array}{l}\text { Avg. } \\
\text { change }\end{array}$ & Sig. \\
\hline Percent of cycle & & & & \\
Extension & 1.8 & 1.6 & -0.2 & n.s. \\
Neutral & 62.7 & 57.6 & -5.1 & 0.03 \\
Mild Flexion & 14.7 & 19.4 & 4.7 & 0.01 \\
Severe Flexion & 1.2 & 2.5 & 1.3 & 0.04 \\
Twisted or Bent & 19.5 & 18.9 & -0.6 & n.s. \\
Duration (sec) & & & & \\
Extension & 0.8 & 0.9 & 0.1 & n.s. \\
Neutral & 20.5 & 18.3 & -2.1 & n.s. \\
Mild Flexion & 4.5 & 5.2 & 0.7 & n.s. \\
Severe Flexion & 0.5 & 0.8 & 0.3 & n.s. \\
Twisted or Bent & 4.5 & 5.9 & 1.4 & n.s. \\
\hline
\end{tabular}


Table 7

Changes in shoulder posture between initial and final independent evaluations. Results of 'paired- $t$ ' analyses.

\begin{tabular}{lcccc}
\hline \multicolumn{5}{c}{ Observed shoulder postures } \\
\cline { 2 - 5 } & $\begin{array}{l}\text { Initial } \\
\text { (mean) }\end{array}$ & $\begin{array}{l}\text { Final } \\
\text { (mean) }\end{array}$ & $\begin{array}{l}\text { Avg. } \\
\text { change }\end{array}$ & Sig. \\
\hline Percent of cycle & & & & \\
Left shoulder $(n=139)$ & & & \\
Neutral & 77.2 & 81.2 & 4.0 & 0.02 \\
Mild Elevation & 20.8 & 17.1 & -3.7 & 0.02 \\
Severe Elevation & 2.0 & 1.2 & -0.8 & 0.03 \\
Right shoulder $(n=141)$ & & & \\
Neutral & 73.3 & 79.8 & 6.4 & 0.002 \\
Mild Elevation & 23.1 & 18.3 & -4.8 & 0.01 \\
Severe Elevation & 2.9 & 1.9 & -1.0 & 0.07 \\
Duration (sec) & & & & \\
Left shoulder $(n=139)$ & & & \\
Neutral & 27.0 & 31.0 & 4.0 & n.s. \\
Mild Elevation & 5.4 & 4.2 & -1.2 & 0.08 \\
Severe Elevation & 0.72 & 0.57 & -0.15 & n.s. \\
Right shoulder $(n=141)$ & & & \\
Neutral & 21.6 & 24.6 & 3.0 & 0.07 \\
Mild Elevation & 4.8 & 4.4 & -0.4 & n.s. \\
Severe Elevation & 0.92 & 0.87 & -0.06 & n.s. \\
\hline
\end{tabular}

19.4 percent for mild flexion $(p<0.01)$ and from 1.2 to 2.5 percent for severe flexion $(p<0.01)$. The percentage of the work cycle spent with the neck extended or twisted decreased, but the differences were not significant. The percentage of the work cycle with the neck in a neutral posture decreased significantly, from 63 percent to 58 percent $(p<0.05)$. Changes in the duration of time spent in any postures were small; no differences were significant. See the lower portion of table 6 for additional information.

In summary, neck postures did not improve as a result of interventions. It is possible that changes made to improve shoulder postures (e.g., lowering overhead reach requirements and reducing horizontal requirements, discussed below) may have required workers to look downward at a steeper angle, resulting in increased neck flexion.

\section{Shoulders}

The results of the shoulder postures are presented in table 7 . There were at least two rounds of independent analyses of left shoulder posture on 139 jobs, while 141 jobs underwent at least two rounds of analysis for the right shoulder. The percentage of the work cycle spent in neutral postures increased significantly between the initial and final observations for both shoulders (from 77 to 82 percent on the left side $(p<0.05)$ and from 73 to 80 percent on the right side $(p<0.005)$. The percentage of the work cycle spent in non-neutral postures decreased between the initial and final observations. Decreases in mild and severe elevation were significant $(p<$ 0.05 ) for the left shoulder. The decrease in mild elevation for the right shoulder was significant $(p<0.01)$ while the decrease in severe elevation was only marginally significant $(p<0.10)$.

Similar results were obtained when considering the duration of time spent in any posture. This time increased for neutral postures and decreased for non-neutral postures. Only two differences were significant (marginally); the time with the left shoulder in mild elevation decreased and the time with the right shoulder in a neutral posture increased.

In summary, the independent evaluations found that shoulder postures improved as a result of interventions that were implemented to reduce or eliminate elevated and/or extended reaches.

\section{Discussion}

The results presented above show that trunk and shoulder postures generally improved as a result of ergonomic interventions implemented during the joint union-management ergonomics program. At the same time, however, neck postures became more stressful. Additional insight to these and other findings is presented below.

\section{Improvements in trunk and shoulder postures}

The detailed independent analyses performed by the university investigators found that the inplant ergonomic teams were generally effective in implementing changes to work station layout such as:

(1) Installing lift tables and elevated racks to raise objects off the floor, thus reducing trunk flexion when reaching to low heights.

(2) Eliminating or reducing horizontal obstructions (e.g., moving guard rails, increasing toe 
space, etc.), thus reducing trunk flexion and/or shoulder elevation when performing forward reaches and assembly tasks.

(3) Eliminating or reducing overhead reaches by lowering the height of items such as storage shelves and overhead monorail conveyors, thus reducing shoulder elevation.

The effectiveness of changes in work station layout can be demonstrated through the use of a case study. Appendix A presents 'pre-change' versus 'post-change' observations obtained by the university researchers to illustrate the effectiveness of ergonomic interventions in reducing postural stresses on one of the study jobs. In this example, a number of work station layout changes were implemented to reduce postural stresses associated with a periodic maintenance activity on a wrapping machine. As a result of these changes neutral trunk postures increased from 13 to 72 percent of the work cycle, neutral left shoulder postures increased from 31 to 88 percent, neutral right shoulder postures increased from 21 to 89 percent, while neutral neck postures decreased from 75 to 58 percent (see table A.1).

The case study presented in the Appendix was one of the more successful ergonomic interventions implemented during the study and should not be interpreted as a typical change. Most of the interventions produced more modest reductions in postural stress. It is also noteworthy that only about 30 percent of the baseline jobs underwent any ergonomic modifications during the course of this study (Silverstein et al., 1990). (Furthermore, not all of these changes were motivated by the presence of awkward postures.) Had additional resources and time been available to modify a larger fraction of the jobs, it is likely that the improvements in trunk and shoulder postures presented in Tables 5 and 7 would have been more impressive.

\section{Increase in awkward neck posture between baseline and follow-up}

While trunk and shoulder postures improved as a result of interventions implemented between the baseline and final analyses, neck postures generally got worse with workers spending a significantly greater portion of work time with their necks in mild to severe flexion (see table 6). This finding was unexpected as we had anticipated observing reductions in postural stress at all of the studied joints. Because the study design did not facilitate scientifically-sound follow-up analyses to determine the causes of this paradoxical result, several explanations are proposed below.

Anecdotal evidence suggests that members of the in-plant ergonomic teams were more concerned with trunk and shoulders postures than with neck postures. During interviews to determine user acceptance of the checklists used in the initial screening of jobs (see 'Methods' section), representatives from one of the four plants requested that the neck questions be removed from the checklist, because 'everybody uses awkward neck postures while performing their jobs'. This comment is at least partially supported by the study data. At baseline, workers maintained neutral trunk postures (standing and sitting, pooled) approximately 79 percent of the time (table 1) and neutral shoulder posture approximately 75 percent of the time (table 4). Neutral neck postures were less common; workers maintained neutral postures only 62 percent of the time (table 3). Because awkward neck postures were so prevalent at baseline, members of the in-plant teams may have been relatively insensitive to jobs with potential neck problems and less likely to instigate corrective actions.

Training may have also influenced the behavior of the in-plant team members in responding to awkward neck postures. The one-week training program and three-day workshop placed high emphasis on the prevention of back and upper extremity disorders while giving neck disorders relatively minor coverage. The examples used in the training programs to illustrate ergonomic improvements generally focused on modifying manual materials handling tasks to reduce the risk of back and shoulder injuries and modifying handintensive assembly jobs to reduce the risk of upper extremity cumulative trauma disorders. Although the role of awkward neck posture as an ergonomic risk factor was mentioned in training, it did not receive nearly the level of emphasis and reinforcement given to the other topics. As a result, members of the in-plant teams may have considered potential neck problems to be of lower priority than potential back or shoulder prob- 
lems. Additional studies are suggested to investigate the influence of training on how in-plant teams establish priorities for ergonomic interventions.

\section{Modifications to work station layout vs. other types of intervention}

Although the in-plant teams were successful in implementing changes to work station layout, there was relatively little success in implementing other types of changes. For example, alterations in the basic design of products and modifications to manufacturing processes for the purpose of reducing ergonomic stresses were difficult to implement and were rarely observed. In general, changes of these types have a longer lead time than layout changes and may not have been feasible to implement during the limited duration of this study. Furthermore, decision-making related to product design and manufacturing processes is frequently done by 'outsiders', i.e., individuals who do not reside in the plant (Joseph, 1986). To improve the ergonomic knowledge-base of corporate managers and engineers responsible for product and process decisions, it is important for these individuals to become more directly involved in in-plant ergonomic activities. It is also important that in-plant committees report their activities to corporate decision makers on a regular basis.

Another explanation for the predominance of work station layout changes in reducing postural stress was the relatively low cost of implementing these modifications. For example, empty pallets were stacked atop each other to raise objects off of the floor in order to reduce trunk flexion (a 'zero' cost fix) or low-cost racks (typically two hundred dollars or less) were purchased to accomplish the same objective. More sophisticated systems such as pneumatic or hydraulic lift tables were still relatively inexpensive (a few thousand dollars) to install. Other changes (such as process and product modifications) were considerably more expensive, and usually required approval from persons outside the ergonomics committee.

\section{Conclusions}

This investigation found that joint in-plant labor-management ergonomic committees were generally successfully in identifying jobs that exposed workers to awkward trunk and shoulder postures and in developing and implementing work place modifications to reduce the time workers spend in awkward postures. These committees were unsuccessful, however, in reducing the time spent in awkward neck postures. Almost all of the successful interventions were based on modifications to work station layout as opposed to changes in product design and/or manufacturing processes.

\section{Acknowledgments and disclaimer}

The authors thank Ms. Juliann Leonard and Mr. Andrew Bigelow for their assistance in the collection and analysis of data. The authors also
Side View

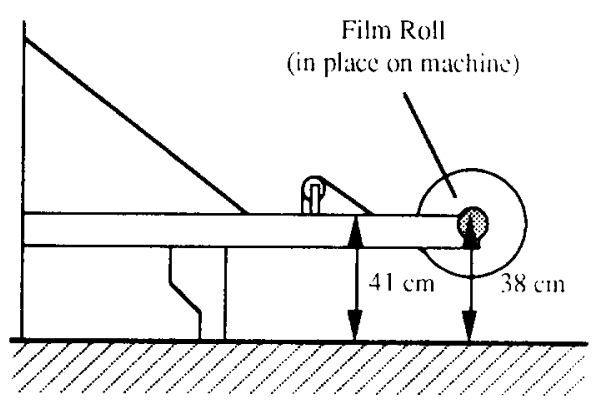

Find View

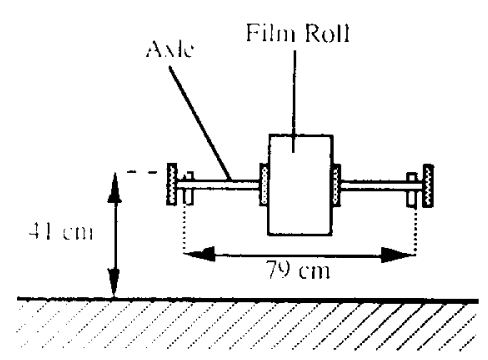

Fig. A.1. Pre-change location of film roll on V-Pack machine. 


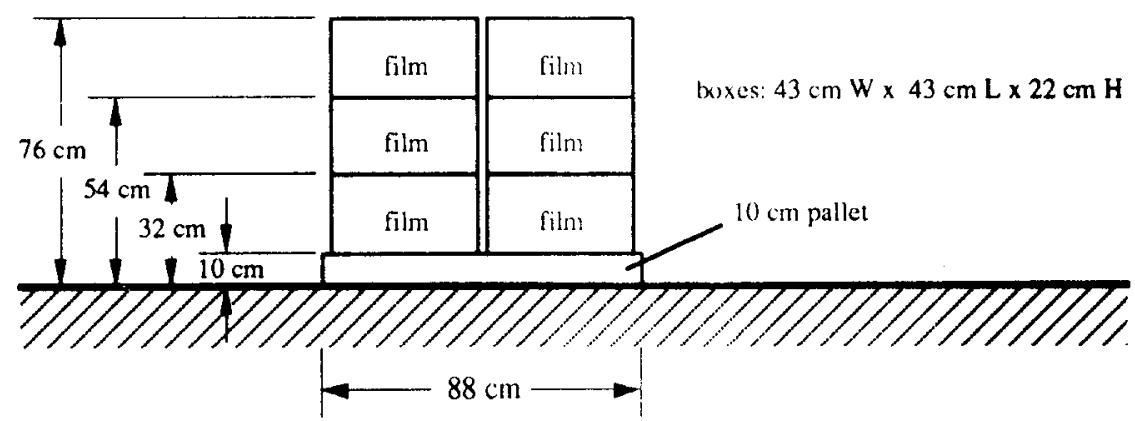

Fig. A.2. Pre-change film stacking, pallet on floor.

thank the Ergonomic Coordinators and Ergonomic Monitors at the participating plant sites for facilitation of collection of in-plant data.

This project was supported by joint funds from the UAW/GM National Joint Committee on Health and Safety, which does not necessarily support or endorse the findings herein and which are solely the responsibility of the authors.

\section{Appendix: A case study}

\section{Job description}

This warehouse job involves using a special machine to wrap small, lightweight parts in an envelope formed from a roll of plastic film. When the roll of film is depleted or when a different width of film is required, the machine operator must perform a roll change. Depending on production requirements, the roll change activity is performed between two and six times per shift.

\section{Pre-change analysis}

\section{Work station layout}

The pre-change location of the roll of plastic film on the wrapping machine was approximately $38 \mathrm{~cm}$ above the floor as shown in figure A.1. This location required the worker to spend a significant amount of time with her back in a flexed posture when changing the film. See table A.1. Prior to the change, new rolls of plastic film were stored in boxes on pallets as shown in figure A.2. Note that the boxes at the bottom of the pallet were only $10 \mathrm{~cm}$ above the floor, requiring the worker to flex her back when obtaining or replacing rolls at this level.
Work elements

In the pre-change configuration, a typical roll change involved the following tasks:

(1) Cut film, remove old roll from axle and carry it to storage location.

(2) Walk to film storage pallet, open box containing new roll.

Table A.1

Results of posture analyses on case study job.

\begin{tabular}{|c|c|c|c|c|}
\hline & \multicolumn{4}{|c|}{ Observed postures } \\
\hline & \multicolumn{2}{|c|}{ Percent of cycle } & \multicolumn{2}{|c|}{$\begin{array}{l}\text { Time in posture } \\
(\mathrm{sec} .)\end{array}$} \\
\hline & $\begin{array}{l}\text { Pre- } \\
\text { change }\end{array}$ & $\begin{array}{l}\text { Post- } \\
\text { change }\end{array}$ & $\begin{array}{l}\text { Pre- } \\
\text { change }\end{array}$ & $\begin{array}{l}\text { Post- } \\
\text { change }\end{array}$ \\
\hline \multicolumn{5}{|l|}{ Trunk } \\
\hline $\begin{array}{l}\text { Stand - Neutral } \\
\text { Stand - Mild }\end{array}$ & 13 & 72 & 9.5 & 30.6 \\
\hline Flexion & 0 & 23 & 0.0 & 8.4 \\
\hline \multicolumn{5}{|l|}{ Stand - Severe } \\
\hline Flexion & 87 & 2 & 70.5 & 3.1 \\
\hline Obscured view & 0 & 3 & 0.0 & 7.0 \\
\hline \multicolumn{5}{|l|}{ Neck } \\
\hline Neutral & 75 & 58 & 17.0 & 22.4 \\
\hline Mild flexion & 24 & 38 & 5.7 & 9.6 \\
\hline Severe flexion & 0 & $<1$ & 0.0 & 0.7 \\
\hline Twisting & 3 & $<1$ & 1.4 & 1.5 \\
\hline Obscured view & 0 & 3 & 0.0 & 7.0 \\
\hline \multicolumn{5}{|l|}{ Left shoulder } \\
\hline Neutral & 31 & 88 & 10.9 & 113.0 \\
\hline Mild elevation & 68 & 10 & 23.8 & 16.0 \\
\hline Severe elevation & $<1$ & 0 & 0.3 & 0.0 \\
\hline Obscured view & 0 & 3 & 0.0 & 6.8 \\
\hline \multicolumn{5}{|l|}{ Right shoulder } \\
\hline Neutral & 21 & 89 & 10.7 & 46.6 \\
\hline Mild elevation & 79 & 8 & 51.8 & 4.6 \\
\hline Severe elevation & $<1$ & 0 & 0.3 & 0.0 \\
\hline Obscured view & 0 & 3 & 0.0 & 6.9 \\
\hline
\end{tabular}




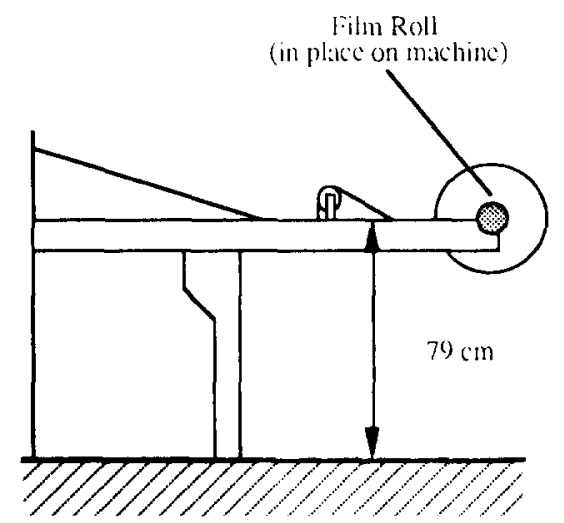

Fig. A.3. Post-change location of film roll on V-Pack machine.

(3) Remove new roll and place on floor.

(4) Roll new roll to machine (distance up to 4.0 meters).

(5) Insert axle to new roll and lift assembly into machine.

(6) Secure new roll in feed mechanism, and splice leader to remnant of old roll.

\section{Posture analysis}

Due to the low height of the machine and the low storage height of boxes on the pallet, the worker performed elements (1), (3), (4), (5), and (6) with her back bent forward. As shown in table
A.1, fully 87 percent of the work cycle was performed with the back in severe flexion. In addition, mild forward flexion of both shoulders was required when performing some of the low reaches.

\section{Ergonomic changes}

Three significant changes were implemented to reduce ergonomic stresses on this job:

(1) The location of the film roll on the machine was raised from $38 \mathrm{~cm}$ to $79 \mathrm{~cm}$. See fig. A.3.

(2) The pallet used for storing film rolls was positioned on a $58 \mathrm{~cm}$ 'backsaver' rack. See figure A.4.

(3) A lift cart was provided for raising, lowering, and transporting rolls. Not only did this eliminate the need to stoop while rolling the roll from storage to the machine, it also eliminated the need to manually lift and lower a heavy $(30 \mathrm{~kg}$ ) load. See figure A.5.

\section{Post-change analysis}

\section{Work station layout}

The need to reach to low locations was ameliorated by raising the height of the film roll on the machine and placing storage pallets on racks. See figures A.3 and A.4.

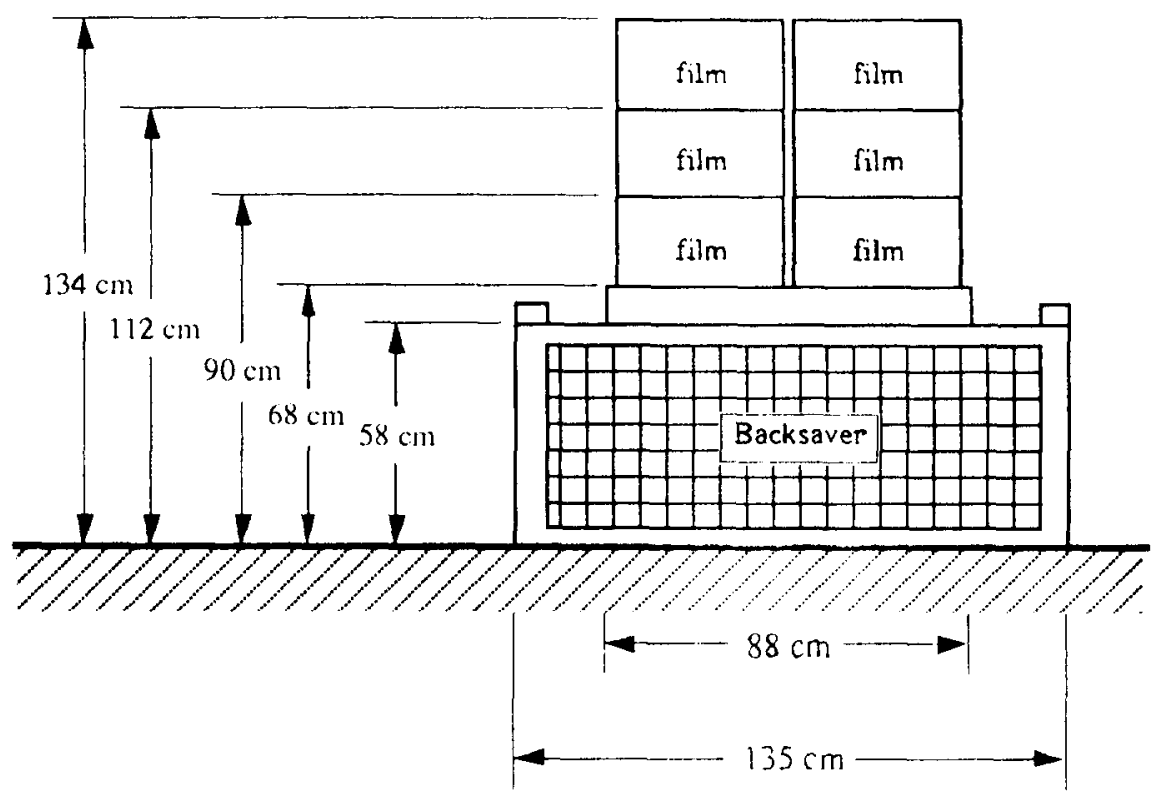

Fig. A.4. Post-change film stacking, pallet on backsaver. 


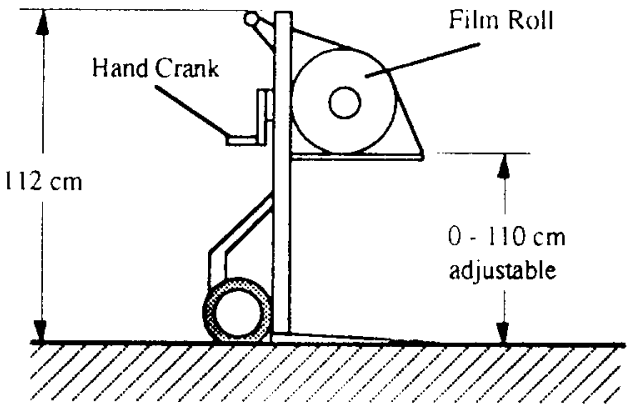

Fig. A.5. Manual lift cart used to move film rolls.

\section{Work elements}

In the post-change configuration, a typical roll change involved the following tasks:

(1) Cut film, use lift cart to remove old roll and axle from machine.

(2) Use cart to transfer used roll to storage location.

(3) Push cart to pallet holding boxes of new rolls.

(4) Remove new roll from box and place on cart.

(5) Push cart to wrapping machine.

(6) Insert axle to new roll, use cart to lower assembly into machine.

(7) Secure new roll in feed mechanism, and splice leader to remnant of old roll.

\section{Posture analysis}

As a result of changes to work station layout and equipment, it was no longer necessary for the worker to position her trunk in severe flexion. The new configuration allowed the worker to maintain a neutral posture for 72 percent of the work cycle. Mild trunk flexion was required during 23 percent of the cycle and a twisted/bent posture was required for only 2 percent of the cycle. Shoulder flexion was also reduced. See table A.1 for additional details.

\section{Summary}

The ergonomic changes implemented on this job substantially reduced awkward trunk postures. There was also a slight reduction in awkward shoulder postures and a slight increase in awkward neck postures.

\section{References}

Andersson, G.B.J., Ortengren, R. and Herberts, P., 1977. Quantitative electromyographic studies of back muscle activity related to posture and loading. Orthopedic Clinics of North America, 8: 85-96.

Armstrong, T., 1986. Ergonomics and cumulative trauma disorders. Hand Clinics. 2: 553-565.

Chaffin, D.B., 1973. Localized muscle fatigue - Definition and measurement. Journal of Occupational Medicine, 15: 346-354.

Corlett, E.N. and Bishop, R.P., 1976. A technique for assessing postural discomfort. Ergonomics, 19: 175-182.

Feldman, R., Goldman, R. and Keyserling, W., 1983. Peripheral nerve entrapment syndromes and ergonomic factors. Amer. J. Ind. Med., 4: 661-681.

Fox, D.J. and Guire, K.E., 1976. Documentation for MIDAS. Statistical Research Laboratory, The University of Michigan, Ann Arbor, 203 pp.

Grandjean, E., 1985. Fitting the Task to the Man. Taylor and Francis, London.

Hagberg, M., 1982. Local shoulder muscular strain - Symptoms and disorders. J. Human Ergology, 11: 99-108.

Hagberg, M., 1984. Occupational musculoskeletal stress and disorders of the neck and shoulder: A review of possible pathophysiology. Int. Arch. Occup. Environ. Health, 53: $269-278$.

Harms-Ringdahl, K. and Ekholm, J., 1986. Intensity and character of pain and muscular activity levels elicited by maintained extreme flexion position of the lower-cervical-upper-thoracic spine. Scandinavian Journal of Rehabilitation Medicine, 1-8: 117-126.

Harms-Ringdahl, K., Ekholm, J., Schuldt, K., Nemeth, G. and Arborelius, U.P., 1986. Load moments and myoelectric activity when the cervical spine is held in full flexion and extension. Ergonomics, 29: 1539-1552.

Hsaio, H. and Keyserling, W.M., 1991. A pilot evaluation of posture behavior during seated tasks. Int. J. Industrial Ergonomics, 8: 313-334.

Hunting, W., Grandjean, E. and Maeda, K.., 1980. Constrained postures in accounting machine operators. Applied Ergonomics, 11: 145-149.

Joseph, B.S.., 1986. A Participative Ergonomics Control Program in a U.S. Automotive Plant: Evaluation and Implications. Ph.D. Dissertation, Center for Ergonomics, The University of Michigan, University Microfilms International, Ann Arbor, MI.

Kelsey, J. and Hochberg, M., 1988. Epidemiology of chronic musculoskeletal disorders. An. Rev. Public Health, 9: 379_ 401.

Keyserling, W.M., 1986. A computer-aided system to evaluate postural stress in the workplace. Am. Ind. Hyg. Assoc. J., 47: 417-425.

Keyserling, W.M., 1990. Computer-aided posture analysis of the trunk, neck, shoulders and lower extremities. In: W. Karwowski, A.M. Genaidy and S.S. Asfour (Eds.), Computer-Aided Ergonomics. Taylor and Francis, London, pp. 261-272.

Keyserling, W.M., Brouwer, M. and Silverstein, B.A., in review. A checklist for evaluating ergonomic risk factors 
resulting from awkward postures of the legs, trunk and neck. Int. J. Indus. Ergonomics.

Keyserling, W.M., Punnett, L. and Fine, L.J., 1988. Trunk posture and back pain: Identification and control of occupational risk factors. Appl. Ind. Hyg., 3: 87-21.

Keyserling, W.M., Stetson, D., Silverstein, B.S. and Brouwer, M.L., in press. A checklist for evaluating upper extremity cumulative trauma disorders. Ergonomics.

Kilbom, A, Persson, J. and Jonsson, B.G., 1986. Disorders of the cervicobrachial region among female workers in the electronics industry. Int. J. Industrial Ergonomics, 1: 3747.

Occupational Safety and Health Administration (OSHA), 1990. Ergonomics Program Management Guidelines for Meatpacking Plants. Publication No. OSHA-3121, U.S. Department of Labor, Washington, DC.

Punnett, L., Fine, L.J., Keyserling, W.M., Herrin, G.D., Chaffin, D.B., 1991. Back disorders and non-neutral trunk postures of automobile assembly workers. Scandinavian Journal of Work, Environment and Health, 17: 337-346.

Sachs, L., 1984. Applied Statistics - A Handbook of Techniques (2nd edition). Springer-Verlag, New York, 707 pp.

Schultz, A., Andersson, G., Ortengren, R., Nachemson, A. and Haderspeck, K., 1982. Loads on the lumber spine: Validation of biomechanical analysis: Measurements of intradiscal pressures and myoelectric signals. J. Bone and Joint Surg., 64A: 713-720.

Silverstein, B.A., Keyserling, W.M., Alcser, K., Richards, S. and Stetson, D.S., 1990. Evaluation of the UAW-GM Ergonomics Pilot Project: Final Report, Department of Environmental and Industrial Health, Ann Arbor, MI: The University of Michigan.

Tichauer, E.R., 1978. The Biomechanical Basis of Ergonomics. Wiley: Interscience, New York.

Tola, S., Riihimaki, H., Videman, T., Viikari-Juntura, E. and Hanninen, K., 1988. Neck and shoulder symptoms among men in machine operating, dynamic physical work and sedentary work. Scandinavian Journal of Work, Environment and Health, 14: 299-305.

Ulin, S.S., Ways, C.M., Armstrong, T.J. and Snook, S.S., 1990. Perceived exertion and discomfort versus work height with a pistol-shaped screwdriver. Am. Ind. Hyg. Assoc. J., 51: 588-594.

Van Wely, P., 1970. Design and disease. Applied Ergonomics, 1: 262-269. 